\title{
Uma abordagem semiótica Aplicada a Objetos Hipermídia Educacionais no SBTVD.
}

\author{
Eráclito de Souza Argolo, PPGIE/UFRGS, eraclito.argolo@ufrgs.br \\ Carlos de Salles Soares Neto, DEINF/UFMA, csalles@deinf.ufma.br \\ José Valdeni de Lima, PPGIE/UFRGS, valdeni@inf.ufrgs.br
}

\begin{abstract}
Resumo. Com o surgimento do Sistema Brasileiro de TV Digital Terrestre - SBTVD-T - um deslocamento no eixo paradigmático dos modelos de produção de conteúdos educativos em teledifusão tornou-se possível. De um modelo unidirecional de difusão da programação televisiva educacional nativa da TV analógica, cuja abordagem pedagógica é behaviorista, evoluimos para uma concepção hipermidiática interativa, onde uma abordagem pedagógica conexionista ganha corpo através do t-learning. Este trabalho tem como objetivo discutir o perfil semiótico na construção de soluções hipermidiáticas educativas na plataforma do Sistema Brasileiro de TV Digital, buscando uma identificação dos aspectos convergentes entre educação, novas tecnologias e comunicação social na produção de conteúdos.
\end{abstract}

Palavras chave. Semiótica, hipermídia, educação, SBTVD.

\section{A semiotic approach Applied to Educational Hypermedia Objects in SBTVD.}

\begin{abstract}
With the advent of the Brazilian Terrestrial Digital TV - SBTVD-T - a shift in paradigmatic axis production models of educational content in broadcasting was made possible. A unidirectional diffusion of educational analog television native programming TV, whose pedagogical approach is behavioral, we evolved into a hypermedia design interactive pedagogical approach where a connectionist become effective through the t-learning. This paper aims to discuss the semiotic construction profile of hypermedia educational solutions on the platform of the Brazilian Digital TV, seeking a convergent identification of aspects of education, new technologies and media in content production.
\end{abstract}

Keywords. Semiótic, hypermedia, education, SBTVD.

\section{INTRODUÇÃO}

Na década de 90 iniciou-se o processo de implantação da TV digital no Brasil. A partir da assinatura do decreto $\mathrm{n}^{\circ}$ 4.901/2003 - Presidência da República - os pilares do Sistema Brasileiro de TV Digital (SBTVD) foram conhecidos, dentre os quais destacam-se, no artigo $1^{\circ}$ do referido decreto, incisos I e II, a democratização da informação (pela promoção da inclusão social, da diversidade cultural e da língua 
pátria) e a criação de uma rede universal de educação a distância, respectivamente (BRASIL, 2003).

No bojo da concepção do SBTVD, há uma perspectiva de superação das dificuldades de acesso à informação e à educação, enfrentadas por parcelas da população, quando da migração de todo o sistema televisivo nacional ao padrão digital. Dado o fato de que, já em 2009, foi atingido o índice percentual de 95,7\% dos lares brasileiros possuidores um aparelho de televisão (IBGE, 2010), vislumbra-se a possibilidade do provimento de acesso à informação e conteúdos interativos por multimeios, de modo universal, devido à capilaridade da rede de comunicação de dados que constituirá o SBTVD.

Do ponto de vista educativo, desde a inauguração dos processos de distribuição audiovisual da informação em teledifusão por broadcasting ${ }^{1}$ no Brasil, ainda nos idos da década de 1950, percebeu-se a TV como um canal viável para a democratização do ensino. Ocorreu a criação de um espaço no qual o saber e o saber fazer podiam ser apropriados, bem como a capacidade de ampliar a percepção pela simultaneidade da visão e da audição tornou-se presente (SILVA, 2001). Porém, a possibilidade de distribuição da informação, de maneira massiva e unidirecional do fluxo das mídias da TV analógica (ou convencional), colocou o telespectador em uma posição de consumidor passivo de conteúdos. Especialmente no caso brasileiro verificou-se, com o passar do tempo, que o viés mercadológico contaminou negativamente a qualidade da produção de conteúdos, levando à priorização de gêneros televisivos que, raras exceções, possuem uma carga pobre em conteúdos formativos. Não obstante, a TV analógica contemplou a população com o acesso, em larga escala, a processos de ensino e aprendizagem a distância quando da implantação de projetos específicos. Monteiro et al. (2008) ilustram algumas iniciativas em TV ao aludirem que "Por ser um recurso acessível à grande maioria da população, na área educacional, a TV já possui uma história de cursos a distância, como por exemplo, TV Escola [...] e o Telecurso 2000 [...]”.

Com o avançar do desenvolvimento dos recursos tecnológicos e a digitalização das formas de produção e veiculação de conteúdos em TV, o caminho da interatividade, em tempo real, através do próprio aparelho televisor, via sistemas nele embarcados, passou a ser factível. Em especial para o caso brasileiro, a definição pelo padrão de infraestrutura de rede japonês Integrated Services Digital Broadcasting Terrestrial version b (ISDB-Tb), que se deu pelo Decreto Presidencial $n^{\circ} 5.820$ de 29 de junho de 2006 (BRASIL, 2006), bem como a adoção do software Ginga ${ }^{2}$, instalado nos aparelhos receptores de TV digital, criaram as condições iniciais para a implantação do Sistema Brasileiro de TV Digital Terrestre (SBTVD-T). Nesta configuração tecnológica, surge a possibilidade de serem veiculados, na rede de teledifusão, conteúdos hipermidiáticos, concebidos e desenvolvidos para contar com o apoio de aplicações em software capazes de realizar processamento de dados e de promover a interação entre telespectador e conteúdo. Uma nova forma de se pensar o papel da teledifusão passou a instigar trabalhos de pesquisa, notadamente na área da Comunicação Social.

\footnotetext{
${ }^{1}$ Trata-se da transmissão e difusão de informação na qual ocorre o envio para muitos receptores ao mesmo tempo.

${ }^{2}$ desenvolvido pela PUC-RIO e Universidade Federal da Paraíba
} 


\section{PESQUISAS RELACIONADAS À TELEDIFUSÃO}

Conforme descrito por Fechini (2001), pesquisas em TV até então vinham refletindo preocupações na busca pela compreensão do poder exercido pela televisão nos sistemas político, social e cultural, sendo que tais estudos adotaram proposições nas quais a TV assume o papel de suporte ao regime econômico, ou ainda como empreendimento mercadológico ou de mediação nas sociedades contemporâneas, dentre outras feições a ela atribuída. Tais abordagens, segundo a autora, derivam das visões de um campo interdisciplinar que orbita a sociologia da comunicação, que aponta a TV como o meio hegemônico no séc. XX.

Em Machado (2000), uma abordagem semiótica voltada à produção de conteúdos, direcionada à qualidade da produção da programação da TV analógica, é dita viável pela aliança entre sua tecnologia e sua capacidade de expressão audiovisual intrínseca. Para tanto, o autor coaduna a visão da produção à visão da recepção, na figura dos produtores e receptores (ou telespectadores), observada a forma de organização das idéias, dos meios e dos recursos de modo culturalmente estratificado, buscando com isso obter a comunicabilidade dos produtos pela observação da intencionalidade na produção de gêneros televisivos.

Em Angeluci e Castro (2010), podemos verificar uma sinalização dos efeitos provocados pela necessidade de criação de modelos interativos e convergentes na produção de conteúdos audiovisuais com o advento do SBTVD. Os autores apontam a necessidade de adoção de uma abordagem paradigmática que leve em consideração o caráter interativo, a perspectiva não linear e a aderência a tecnologias multiplataformas que extrapolam os limites da própria TV digital. Entretanto, esta proposição, ainda segundo os autores, enfrenta resistências, uma vez que o modelo de negócio adotado pelos teledifusores não acomodou, ainda, as possibilidades de construção interativa aos gêneros televisivos.

As potencialidades de interação proporcionadas pelo SBTVD exigem a preocupação com aspectos de construção dos conteúdos. Há de se destacar a necessidade da observação da não-linearidade dos programas em TV digital, que rompem com o modelo tradicional de roteirização linear - início, desenvolvimento, clímax e desfecho - e que implica uma abordagem modular, onde um "módulo visual" pode ser relacionado a outros e pode, per se, possuir conteúdo semântico (ANGELUCE e CASTRO, 2010).

\section{O POTENCIAL HIPERMÍDIA DO SBTVD}

Em Barroso e Schwabe (1998), há a descrição da estrutura de navegação de uma aplicação hipermídia, proposta como sendo classes navegacionais que são organizadas num modelo conceitual de classes de domínio, de acordo com os requisitos da aplicação a ser projetada. As classes navegacionais são os nós, os elos, a estrutura de acesso e o roteiro pré-definido. Barros e Rezende (2005) complementam a descrição de aplicações hipermídia ao afirmarem que se trata de sistemas computacionais, onde podem ocorrer ligações interativas e não sequenciais entre nós de informação, tal como ocorre com os hipertextos, sendo que estes nós, na verdade, se constituem nas mídias que comporão o objeto hipermidiático. Em outras palavras, o objeto hipermídia é construído por composição de mídias, resultando num conjunto estruturado de itens informacionais que 
é navegável, ou seja, o objeto hipermídia pode ser processado através de sua estrutura de acesso (composta por menus e índices hierárquicos). Os elos, por sua vez, interligam os nós e são ativados por âncoras (palavras marcadas ou botões). Em Nunes Filho (2003) é feita uma caracterização dos objetos hipermídia:

O principal traço do que podemos denominar hipermídia é a conjunção básica de três elementos que se associam a outros: imaterialidade, interatividade e velocidade. Isso implica em afirmar que os diferentes processos de construção sígnica na esfera digital operam com informações vinculadas, interconexões de narrativas, multiplicidade, instantaneidade e estruturação não linear. (NUNES FILHO, 2003, p.57)

O autor pondera, assim, que a forma como um ambiente hipermídia é estruturado e acessado adere a um modelo semiótico que possui interfaces com o usuário numa representação aberta, trazendo consigo um volume de informações capaz de produzir novas referências sígnicas de modo gradual.

Como já mencionado, o SBTVD adotou o software Ginga, um middleware ${ }^{3}$ embarcado nos aparelhos receptores de tv digital, que se utiliza das definições de uma linguagem declarativa, denominada NCL, para executar aplicações hipermídia. Assim, há a possibilidade da aplicação dos conceitos hipermidiáticos na plataforma do SBTVD por agregação dos elementos de mídia sincronizados, que se tornam módulos relacionados entre si, interligados através de cadeias temporais e sobre os quais o middleware atua como software controlador, permitindo a seleção do "o que" (módulos ou nós de informação), do "onde” (definido por regiões na tela do aparelho de TV) e do "quando" (o momento adequado para o acionamento de um determinado elo). Angeluce e Castro (2010) afirmam:

[...] o conteúdo, agora interativo, pode também partir da lógica nãolinear, utilizando áudio, imagens e dados separados ou juntos. Isso tornará a programação (em termos de conteúdos - grifo nosso), de um lado, muito mais complexa no campo da produção, mas, por outro, muito mais interessante e atraente para as audiências. (ANGELUCE e CASTRO, 2003, p.7)

\section{APRENDIZAGEM EM TV DIGITAL}

As teorias de aprendizagem que vêm orientando a promoção da educação contemporânea estão ligadas, de algum modo, ao Comportamentalismo e ao Construtivismo. Outra corrente de pensamento, esta mais próxima das aplicações das Novas Tecnologias de Informação e Comunicação (NTIC), é a do Conexionismo. Cabe uma breve discussão sobre estas correntes como se segue.

\section{IV.1 - Comportamentalismo (Behaviorismo)}

\footnotetext{
${ }^{3}$ Middleware é uma camada de software posicionada entre o código das aplicações e a infra-estrutura de execução (plataforma de hardware e sistema operacional). Um middleware para aplicações de TV digital consiste de máquinas de execução das linguagens oferecidas, e bibliotecas de funções, que permitem o desenvolvimento rápido e fácil de aplicações. (disponível http://www.ginga.org.br/pt-br/sobre)
} 
O norte-americano John Broadus Watson (1913), em seu trabalho intitulado "Psicologia: como um behaviorista a vê" (trabalho que foi consagrado como "Manifesto do Behaviorista"), defende no Comportamentalismo a ideia de que o foco dos processos de Ensino e Aprendizagem deve ser direcionado a análise do comportamento humano baseado num binômio estímulos externos/respostas, o que privilegiaria, assim, o objetivo em detrimento dos processos cognitivos individuais. Trata-se de uma abordagem de previsão e controle da conduta humana pela observação do meio no qual o indivíduo vive, que acaba por deflagrar um processo de condicionamento operante. Numa síntese da proposição do Comportamentalismo, é possível verificar que a abordagem propõe a estruturação rígida e compartimentalização do conhecimento, numa perspectiva onde são subestimadas a sua complexidade e a multiplicidade de contextos onde ele é aplicável. No professor reside, de modo exclusivo e autoritário, o conhecimento, cabendo ao aluno o papel de mero receptor de informações (disponibilizadas de forma repetitiva visando a internalização), que deve ser estimulado de modo específico e que reponde de maneira adequada (BRANCO E BARBAS, 2012).

\section{IV.2 - Construtivismo}

O construtivismo traz em seus fundamentos as proposições do psicólogo e epistemólogo suíço Jean William Fritz Piaget (1896-1980) - teoria da Construção do Conhecimento ou Epistemologia Genética. Em linhas gerais, o construtivismo preconiza que a inteligência e o conhecimento se manifestam a partir da interação do homem com o meio e, em termos pedagógicos, é centrado no aluno.

Atribuído ao filósofo russo Lev Semenovitch Vygotsky (1896-1934), o Sócioconstrutivismo contribuiu para a corrente de pensamento construtivista pela proposição da apreciação do meio social, a partir do qual são promovidas interações sociais capazes de levar ao aprendizado e o desenvolvimento do indivíduo aprendente. Aspectos emocionais permeiam a visão vygotskiana. A motivação (fator motriz), e a afetividade assumem papel relevante na geração do pensamento. Agrupados, a interação existente entre os elementos envolvidos no processo de Ensino e Aprendizagem (alunos e alunos, alunos e os artefatos culturais e alunos e professores), permite a construção sóciocultural do conhecimento. Surge a idéia de Zonas de Desempenho (ZD), divididas em Zona de Desempenho Atual (ZDA) e Zona de Desempenho Proximal (ZDP), sendo que na ZDA prepondera o conjunto de capacidades do aluno para a resolução de problemas de modo autônomo, enquanto que na ZDP prepondera a idéia de colaboração entre alunos, artefatos culturais e professores (BRANCO E BARBAS, 2012).

\section{IV.3 - Conexionismo (ou Conectivismo)}

O canadense George Siemens (Athabasca University de Alberta - Canadá) vem se destacando no desenvolvimento de teorias sobre os impactos da era digital nos processos de aprendizagem. Ele propõe a transposição da visão de produção do conhecimento construtivista (interação do aluno com o meio), para a produção centrada num ambiente de rede, em especial de caráter cibernético, na qual o conhecimento encontra-se distribuído numa rede social de ligações (ou conexões). Na visão do pesquisador, o fenômeno das redes sociais online afeta as formas de interação entre pessoas, informações e, consequentemente, das pessoas com o conhecimento, que agora passa a ser dependente da conexão entre os vários intervenientes. Em sua publicação artigo "A Learning Theory for the Digital Age” (2004), George Siemens aponta tendências 
para o aprendizado nesta era cibercultural, assinalando os seguintes aspectos da sociedade conectada:

- A variedade e a mutabilidade das opiniões dos aprendentes em relação aos possíveis campos do conhecimento;

- A importância do aprendizado informal na experiência pessoal do aprendizado, influenciado pelas associações coletivas, redes de relacionamento pessoal e pela realização de tarefas relacionadas;

- A sua percepção de que o aprendizado ocorre ao longo de toda a vida, não sendo possível separar o aprendizado do trabalho, que podem até mesmo se confundir;

- A reconfiguração de nossos cérebros a partir do uso de ferramentas tecnológicas;

- A concepção de que o indivíduo e o coletivo organizacional são ambos aprendentes;

- Os processos de aprendizado preconizados por teorias anteriores, especialmente a cognitiva, pode ser transferido ou suportado pela tecnologia;

- Os saberes “como" e "o que” passam a ser complementados pelo saber "onde” encontrar o conhecimento necessário.

Assim, Siemens desenvolve o texto estabelecendo princípios do conexionismo a partir dos quais propõe um ambiente nebuloso no qual se dá a aprendizagem e onde o indivíduo nem sempre pode controlar seus elementos centrais. A aprendizagem pode vir a ser fruto de conhecimento acionável, externo ao aprendente, bem como o conjunto de conexões que nos permitem aprender mais assume maior relevância do que aquilo que conhecemos (BRANCO E BARBAS, 2012). Pode-se inferir, sob esta ótica, que a produção e retenção do conhecimento deixam de ser processos unicamente dependentes do indivíduo e são transladados para o ambiente cibernético. Podemos observar uma manifestação desse pensamento conexionista em Parente (2004), quando o autor afirma:

Um dia, os teóricos e historiadores da comunicação vão se dar conta de que pensar em rede não é apenas pensar na rede, que ainda remete à idéia de social ou à idéia de sistema, mas é sobretudo pensar a comunicação como lugar da inovação e do acontecimento, daquilo que escapa ao pensamento da representação. Neste dia, a comunicação terá se tornado, para além de suas tecnologias, fundamento. (PARENTE, 2004, p.92)

\section{IV.4 - A TV HIPERMIDIÁTICA}

O governo brasileiro, através da extinta Secretaria de Educação a Distância - SEED/ Ministério da Educação - MEC), implantou em 1996 o canal TV Escola. O projeto, dentre outros objetos, busca promover o aperfeiçoamento de professores, bem como apoiar o processo de ensino e aprendizagem em prol da qualidade do ensino. Com cursos veiculados através do sistema de teledifusão aberto analógico, sua proposta pedagógica mostrou-se centralizada devido aos limites que a solução tecnológica impunha. A abordagem comportamentalista, com conteúdos previamente definidos e conhecimento residente no professor conteudista, mostrou-se a mais aplicável. Após 2011, as funções da SEED foram transferidas para a Secretaria de Educação Continuada, Alfabetização, Diversidade e Inclusão (SECADI/MEC).

Com o surgimento da interatividade em TV digital, o cenário hipermidiático torna-se concebível na teledifusão. Monteiro et. Al (2008) esclarecem: 
...o usuário pode agora interagir com o conteúdo apresentado, permitindo direcionar a exploração desse conteúdo, buscar novas fontes de informação, trocar mensagens com outros usuários e participar de simulações. Estes recursos respeitam os limites e habilidades de cada aprendiz, tornando-o livre para construção do seu conhecimento, interagindo como preferir com o conteúdo que está sendo apresentado. (MONTEIRO et Al, 2008, p.4)

Na visão dos autores Arbex, Sens e Spanhol (2009), com o advento do SBTVD materializou-se a possibilidade de se abandonar o modelo de transmissões massificadas e unidirecionais em prol de um modelo de comunicação bidirecional, onde a personalização a o estabelecimento de preferências individuais transforma o mero expectador em um potencial usuário, capaz de consumir conteúdos e de também gerá-lo. A quebra da linearidade do fluxo da programação se dá pela possibilidade de gravação, pausa, retorno a pontos específicos ou mesmo a retomada do fluxo linear através do controle remoto. A mudança do perfil de telespectador para usuário, segundo os autores, ocorreu de forma gradual. Esse processo de migração nos é apresentado em termos de níveis de interação, quais sejam: o nível " 0 ” (TV preto e branco com a possibilidade apenas da troca de canais, ligar/desligar o aparelho e regulagens de volume, brilho e contraste); o nível "1" (surgimento do controle remoto e a navegação por entre os diversos canais por zapping); o nível "2" (possibilidade de gravação, fragmentação e leituras não lineares de conteúdos audiovisuais); o nível “3” (interações do telespectador com a equipe de produção através de telefones e internet, afetando a programação) e; o nível "4" (onde surge a TV interativa, com interação reativa que é viabilizada por mecanismos computacionais integrados ao aparelho televisor). Foi proposto por Montez e Becker (2005), mais três níveis de interação: nível “5” (ao telespectador é permitido além de escolher o conteúdo, submeter vídeos de baixa resolução que for capaz de produzir à produtora pelo canal de interação); nível “6” (que supera o nível " 5 ” pela qualidade das mídias que o telespectador pode produzir e submeter devido ao aumento na largura de banda do canal de interatividade) e; nível "7” (dito de interatividade plena, onde o telespectador pode gerar conteúdo e sua produção pode ser veiculada, como ocorre na internet).

O MEC procurou avançar no modelo da TV Escola com a proposição da TV Escola Digital Interativa, mas segundo Arbex, Sens e Spanhol (2009), devido à falta de sintonia política entre os projetos governamentais de Educação a Distância e as ações em TV Digital, o resultado obtido com essa iniciativa destoou absolutamente daquilo que a tecnologia digital desenvolvida para TV aberta permite. Os autores assinalam, entretanto, que tais esforços rumam à efetivação do conceito de convergência entre tecnologias computacionais e televisivas da internet aplicáveis à educação, denominado t-learning (que, ainda segundo os autores, consiste de aplicação dos conceitos de Educação a Distância mediada pela TV digital interativa). Há, portanto, indicações de que a produção de ambientes educacionais hipermidiáticos e o emprego de ferramentas colaborativas são viáveis em SBTVD, havendo condições para a produção de conteúdos educacionais de caráter pedagógico potencialmente conexionista nesta plataforma tecnológica.

\section{DISCUSSÃO SEMIÓTICA}

A Semiótica de Charles Sanders Peirce (1839-1914), trata da relação entre o signo e seu referente por uma tricotomia: do ícone (primeiridade, o signo e sua qualidade), do índice (secundidade, objeto e o fato) e o símbolo (terceiridade, o 
interpretante e sua existência). O ícone, na perspectiva semiótica peirciana, possui relações de similaridade (analogia), podendo ou não o objeto representado por ele existir. O índice, por sua vez, faz a correspondência de fato, causa e efeito, com seu objeto. Por último, o símbolo se constitui no fundamento da imposição de uma relação da representação com seu objeto. Santaella (2005), afirma:

A primeiridade aparece em tudo que estiver relacionado com acaso, possibilidade, qualidade, sentimento, originalidade, liberdade, mônada. A secundidade está ligada às idéias de dependência, determinação, dualidade, ação e reação, aqui e agora, conflito, surpresa, dúvida. A terceiridade diz respeito à generalidade, continuidade, crescimento, inteligência. A forma mais simples da terceiridade, segundo Peirce, manifesta-se no signo, visto que o signo é um primeiro (algo que se apresenta à mente), ligando um segundo (aquilo que o signo indica, se refere ou representa) a um terceiro (o efeito que o signo irá provocar em um possível intérprete). Santaella (2005, p. 7)

\section{V.1 - SEMIÓTICA HIPERMIDIÁTICA}

Aplicar a semiótica aos objetos de aprendizagem hipermidiáticos traz em seu âmago a intencionalidade. Assim como pode ser percebido em Braga et. Al (2009), o princípio semiótico da significação reside na organização de quaisquer representações, em termos de processos e procedimentos, de leitura.

Uma identificação qualitativa, própria de seu modo de ser, relacionada a imagens e objetos da representação e a maneira como essa relação se estabelece (interpretante), permitem interpretações de fato e interpretações potenciais. Trata-se aqui da produção de abstrações que a corporeidade da imagem (cores, luzes e outras substâncias) pode suscitar. Ao compor uma hipermídia por agregação de diversos nós (informação), o objeto resultante torna-se um conjunto de signos que pode, por si só, também se constitui num novo signo. A relação entre imagem e referente pode ser estabelecida de maneira indireta ou por relações naturais ou culturais, por codificação que, ao ser atualizada, gera um interpretante. A figura 1 busca ilustrar este raciocínio.

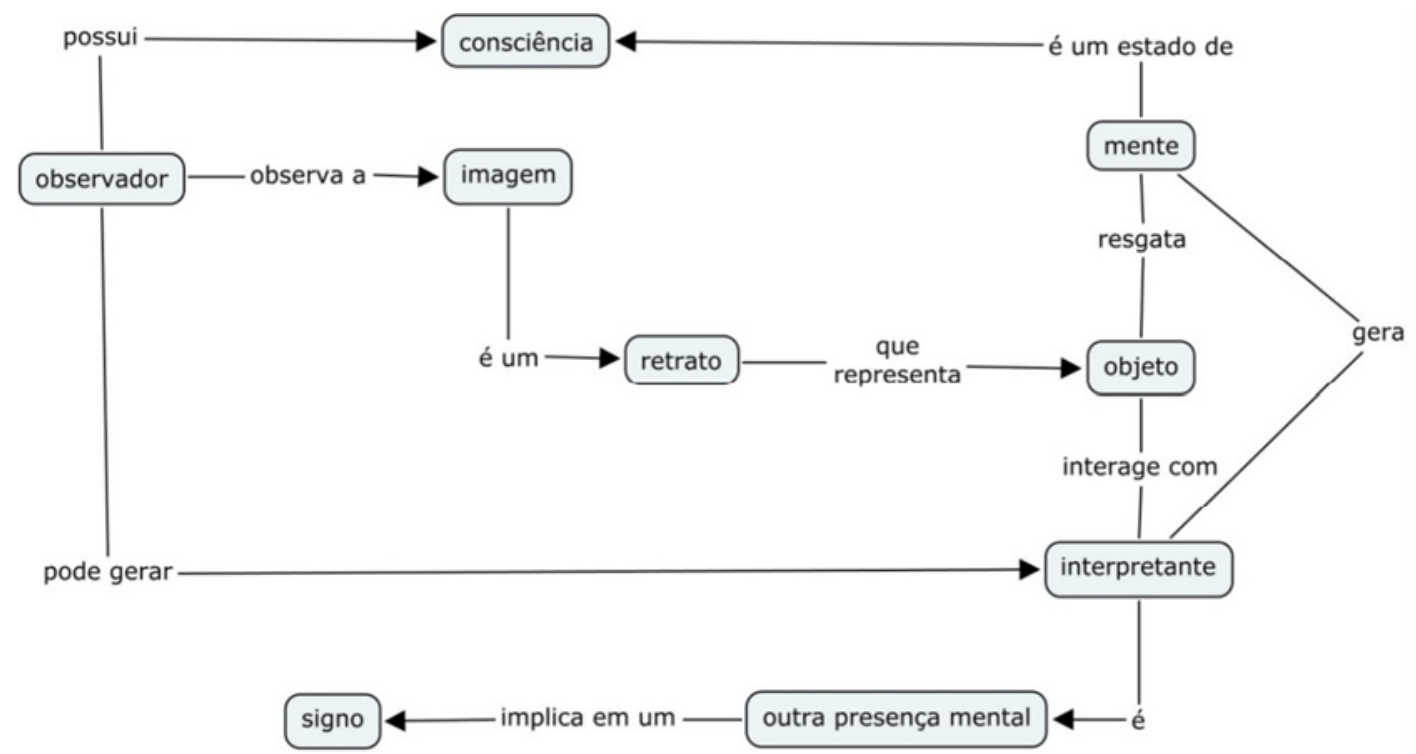


Os vídeos, tanto quanto a fotografia, o cinema, a TV e a holografia, são enquadrados no paradigma fotográfico, no qual há a conexão dinâmica e captação física de fragmentos do mundo visível, prestando-se à documentação informativa e que possuem um poder referencial sobre aquilo que existe na realidade (SANTAELLA, 2005, P.112). Ainda segundo a autora, os vídeos são mídias que combinam áudio e imagem, sendo que, no caso dos videodocumentários, há uma inserção no mundo dos signos das linguagens híbridas, pois possuem gênese na mistura de linguagem verbal e imagem (tanto quanto ocorre com a TV).

Na construção de objetos de aprendizagem hipermidiáticos, deve-se levar em conta a interação do telespectador/usuário com os nós (informações midiáticas) sob o foco da semiótica. Em Candido, Valentim e Contani (2005), é feita uma análise sobre os estados mentais de uma pessoa diante de um grande volume de informação. Segundo os autores, uma multiplicidade incontrolável de informações pode remeter uma pessoa a um estado semiótico de primeiridade, no qual forma-se uma consciência imediata não analisável, onde o sujeito vê-se lançado ao acaso, ausente de consciência crítica e sem ação. Certo grau de desorganização pode levar à indeterminação, ao caos, com potenciais impactos afetivos de estresse, depressão, angústia, dentre outros. Os autores afirmam que a secundidade está ligada às experiências, relaciona-se ao esforço pela materialização do índice, e a terceiridade é a aplicação de uma camada interpretativa, que faz a união do primeiro com o segundo, produzindo valor cognitivo. Assim, o produto cognitivo é dependente da interpretação e ação em relação a uma determinada situação percebida, e sua produção se baseará no suporte dos signos dispostos em um cenário, permitindo a compreensão do problema (assunto), que leve aos caminhos de uma solução ajustada.

O fato de um objeto de aprendizagem hipermídia ser, em si, uma composição de nós midiáticos (informações) deve nos remeter ao tratamento adequado do gradiente cognitivo que se pretende alcançar, observadas as cargas cognitivas que cada nó pode conter e a forma mais adequada de organização e disposição das informações. Volumes adequados de informação e a atenção para com a organização do hiperdocumento, através da concepção de elos e âncoras ajustados, devem ser observados.

\section{V.2 - A ESTÉTICA EM TV DIGITAL}

Ao pensarmos em teledifusão no Brasil, remetemo-nos às perspectivas da produção artísticas que, segundo Arantes (2005), passou por um processo de revigoramento nos idos finais de 1970. A autora assinala o surgimento no Museu de Arte contemporânea da Universidade de São Paulo de uma iniciativa de implementação de uma política cultural de incentivo à produção de jovens artistas pelas mãos do Prof. Walter Zanini. A partir de então, já nos anos 1980, ocorre uma proliferação de experimentações da aplicação de meios tecnológicos e comunicacionais no meio artísticos, dos quais destacam-se, dentre outras, a utilização de vídeos e holografias, "telefones, fax, televisão de varredura lenta (slow scan tv), rádio, videotexto, rede de computadores pessoais e[...] satélites” (ARANTES; ARANTES, 2005, p.57), que evidenciaram a preocupação do mundo das artes nacional com a utilização de novos meios de expressão a partir da gênese tecnologia/comunicação. Ainda segundo Priscila Arantes, a partir de 1977 percebe-se que a ubiquidade, a imaterialidade e a simultaneidade da prática artística passam a ser exploradas, num processo de 
rompimento com o sistema de galerias e circuitos tradicionais de exposições, permitindo ainda o surgimento de uma arte participativa e dialógica.

Ao se observar a convergência entre arte e tecnologia, também é possível imaginar uma proposição das hipermídias que explorem o poder comunicacional semiótico e as capacidades interativas existentes no SBTVD, como é possível perceber na fala que se segue:

[...] as experimentações em animação e cinema de animação são alguns exemplos, e uma outra linha de trabalho que, atenta à teoria da cibernética e às possibilidades de feedback oferecidas pelas tecnologias informacionais, procura focalizar seus estudos no campo da interatividade, isto é, na participação do interator a partir da mediação de uma interface. (ARANTES, 2005, p.59)

\section{CONCLUSÕES}

A interatividade em TV digital pode contribuir para com os processos cognitivos, pois possui em sua concepção tecnológica um caráter hipermidiático que pode comportar a produção de conteúdos carregados de proposições semióticas. A exposição de nós informacionais (mídias) aos telespectadores, organizados numa estrutura navegacional, deve ser pensada sob a perspectiva da intencionalidade. Os potenciais efeitos cognitivos do t-learning não são ainda conhecidos, mas o fato de sua proposta possuir interseções com as concepções do e-learning, indica haver viabilidade em suas aplicações. De modo adicional, o histórico da teleducação no Brasil aponta para um possível grau satisfatório de aceitação do t-learning por parte da população, já habituada a lidar com a tecnologia televisiva.

A possibilidade de utilização da teledifusão digital como mecanismo de distribuição da informação e a possibilidade de elevados graus de interação que a sua tecnologia em hardware e software permitem, poderão proporcionar a concepção e o desenvolvimento de novos paradigmas educacionais televisivos. Cumulativamente, a capilaridade da infraestrutura que lhe dará suporte traz uma perspectiva de abrangência de inclusão digital e social sem precedentes. A familiaridade com que a população em geral trata a tecnologia da teledifusão e a tradição histórica de produção estética alinhada aos aspectos cultural e artístico de seus conteúdos, apontam para uma possibilidade de maior adesão dos telespectadores aos processos de ensino e aprendizagem baseados em t-learning, devendo haver uma convergência não apenas entre a educação e a tecnologia, mas também de esforços conjuntos entre estas áreas e a de comunicação social.

\section{Referências Bibliográficas}

ANGELUCI, Alan C. B.; CASTRO, Cosette. Oito Categorias para Produção de Conteúdo Audiovisual em Televisão Digital e Multiplataformas. Comunicologia n.0x, 2010. 21 p.

ARANTES, Priscila. Arte e Mídia no Brasil: Perspectivas da Estética Digital. São Paulo: SENAC, 2005.190p.

ARBEX, Dafne F.; SENS, André L.; SPANHOL, Fernando. TV Digital Interativa e EAD: a produção de conteúdos para programas educativos. In: Simpósio 
Internacional de Competências em Tecnologias Digitais Interativas na Educação, 2009, Campinas, SP. II Simpósio Internacional de Competências em Tecnologias Digitais Interativas na Educação, Campinas, SP: UNICAMP, 2009. p. 26-42.

BARROS, Suzana S.; REZENDE, Flávia. A Hipermídia e a Aprendizagem de Ciências: Exemplos na Área da Física. Fisica na Escola, v.6, n.1, 2005. 6p.

BARROSO, Natacha G.; SCHWABE, Daniel. Projeto de Navegação em Aplicativos Hipermidia orientado ao Usuario.

BRAGA, Marta C. G.; CASTRO, Luciano P. S.; BRAGA, Ana R. G.; SOUSA, Richard P. L. Análise Semiótica da Interface do Learning Object (LO) Portal EduMusical e o conceito de conservantismo. In: $4^{\circ}$ Congresso Nacional de Ambientes Hipermídia para Aprendizagem (conahpa), Florianópolis, SC, 2009.

BRANCO, Paulo; BARBAS, Maria. Teorias de Aprendizagem e T-learning: Uma Análise Histórica da Utilização da Televisão em Educação. In: Congresso Internacional TIC e Educação, 2012, Lisboa, Portugal. II Congresso Internacional TIC e Educação, Lisboa, Portugal: Instituto de Educação da Universidade de Lisboa, 2012. p.37153732.

BRASIL. Casa Civil. Institui o Sistema Brasileiro de Televisão Digital - SBTVD, 26 novembro 2003. Disponivel em:

<http://www.planalto.gov.br/ccivil_03/decreto/2003/D4901.htm>. Acesso em: 20 outubro 2012.

. Casa Civil. Implantação do Sistema Brasileiro de Televisão Digital

Terrestre - SBTVD-T, 29 junho 2006. Disponivel em:

<http://www.planalto.gov.br/ccivil_03/_Ato2004-2006/2006/Decreto/D5820.htm>.

Acesso em: 20 outubro 2012.

CANDIDO, Carlos A.; VALENTIM, Marta L. P.; CONTANI, Miguel L. Gestão

Estratégica da Informação: semiótica aplicada ao processo de tomada de decisão.

Datagrama Zero,v.6, n.3. Rio de Janeiro. 2005.

IBGE. Pesquisa Nacional por Amostra de Domicílios 2009. PNAD, v. 30, Rio de Janeiro: IBGE, 2010.

FECHINI, Yvana. Televisão e Semiótica: Uma Mudança na Perspectiva de Análise. Galáxia, n.1, 2001. 7p.

MACHADO, Arlindo. A televisão levada a sério. São Paulo: Senac, 2000.

MONTEIRO, Bruno S.; PROTA, Thiago M.; SOUZA, Fernando F.; GOMES, Alex

S. Desenvolvimento de Objetos de Aprendizagem para TVDi. In: Simpósio

Brasileiro de Informática na Educação, 2008, Fortaleza, CE. XIX Simpósio Brasileiro de Informática na Educação. Porto Alegre, RS : Editora da SBC, 2008. v. 1. p. 198-206.

MONTEZ, Carlos; BECKER, Valdecir. TV Digital Interativa: conceitos, desafios e perspectivas para o Brasil. Florianópolis: Ed. da UFSC, 2005. $2^{\mathrm{a}}$ edição

NUNES FILHO, Pedro. Processos de Significação: Hipermídia, Ciberespaço e Publicações Digitais. Forum Media, n.6, 2003. 9p.

PARENTE, André (org). Tramas da rede: novas dimensões filosóficas, estéticas e políticas da comunicação. Porto Alegre: Sulinas, 2004. 303p.

SANTAELLA, Lúcia. Semiótica Aplicada. Pioneira Thomson Learning. 2005. $1^{\text {a }}$ Edição. 
SILVA, B. D. D. Questionar os pressupostos da utilização do audiovisual no ensino: audiovisual / rendimento da aprendizagem / democratização do ensino. Repositorium, 2001. Disponivel em: <http://hdl.handle.net/1822/530>. Acesso em: 16 outubro 2012 